\title{
Multi-optimization of process parameters for machining of a non-conductive SiC ceramic composite by non-conventional machining method
}

\author{
Pallavi Chaudhury* and Sikata Samantaray \\ S 'O' A University, Iter, BBSR-751030, Odisha, India
}

Received: 4 November 2019 / Accepted: 15 August 2020

\begin{abstract}
The objective of the study is to predict the optimized set of the input parameters for the machining of non-conductive silicon carbide $(\mathrm{SiC})$ by electric discharge machining (EDM). The insulated SiC ceramic composite machining was performed with 4 volumes (by percentage) of carbon nano (CNT) the SiC, which makes it electrically conductive. SiC has very good mechanical properties due to its widespread application in the aerospace, MEMS, and bio-sensor industries. This application requires a highly precise machining hole with a good surface quality that can be processed by machining processes such as EDM. The input parameters in this study are differing by three levels and the experimentation has been done by $\mathrm{L}_{27}$ orthogonal array. Four output parameters such as material removal rate (MRR), plasma flushing efficiency (PFE), surface-roughness (SR) and recast layer thickness (Rlt) for has been calculated for the detailed experimental analyses. In this research, a comparative analysis between the Multi-attribute management mechanisms (MADM) i.e. WPCA, MOORA \& MOORA, and WPCA was conducted. The statistical analysis was also conducted to determine the impact of input parameters on performance measures. The study concluded that by integrating MOORA 's method with a PCA, the highest MRRs of $2.56 \mathrm{~mm}^{3} / \mathrm{min} \& 78 \%$ PFE, lowest SR $2.1 \mu \mathrm{m}$, and Rlt $2.56 \mu \mathrm{m}$ were obtained, with an experimental testing error of 5 percent.
\end{abstract}

Keywords: Electrical discharge machining / non-conducting ceramic / multi-optimization technique / weighted principal component analysis / material removal rate

\section{Introduction}

In the present scenario of industrial miniaturization ceramic reinforced composites are being greatly used for its excellent mechanical properties like high hardness, wear resistance, etc. owing to its difficulty during machining. In general conventional machining process leads to failure of machining of the ceramic composite due to its brittleness but on the other side, the conventional machining process is easy to handle. However, it is difficult to machining complex geometrical shapes for these types of hard ceramic composite by the traditional machining process. Electrical discharge machining process (EDM) is one of the most versatile machining processes to machine these intricate shapes without any physical contact with the workpiece. This process includes an electro-thermal material erosion method by involving a tool electrode and work electrode (workpiece) which are being submerged inside an electrical conductive di-electric liquid. With sufficient current and

\footnotetext{
* e-mail: Pallavi.chaudhury@gmail.com
}

voltage, the spark ignites between both the electrodes (workpiece and tool), and the ion moves towards the workpiece surface by breaking the di-electric medium which is conductive. This high voltage spark generates high pressure and temperature at the exact localized surface of the workpiece and the material starts melting and vaporizing. This process leads to the formation of small carters on that surface.

Silicon carbide $(\mathrm{SiC})$ ceramics are considered as potential contestants for diverse usage for the environment, by sophisticated engineering applications. SiC Ceramic as a membrane for water filtration is very easy to use and clean. They are extremely hard and durable $[1,2]$. Due to the high usage of SiC Ceramic-composite in industrial practice, attention has been also focused on the improvement in their physical properties by fabricating ceramic composite. As a result, a significant amount of improvements in their structures can be achieved due to which it can be used in some functional applications in place of metal and its alloy like biomedical implants, electronic chip, heat exchangers in thermal power plant, wear resistance parts and as various coatings over metal to 
increase mechanical properties, like their high hardness, chemical inertness and high electrical and thermal insulating properties [3]. This potential ceramic composite has also ability to replace metal and its alloys (Be-Cu alloy) in thermal industry [4]. But at the same time, the above application requires a highly finished surface with dimensionally accurate machined holes. To achieve the required quality EDM is a good option for machining the ceramic material by eliminating the insulating criteria. For this, any functional material (metal particle) reinforcement is needed which can rise the electrical conductivity by $100 \Omega \mathrm{cm}$ [5-7]. In precise, the remarkable mechanical behavior and outstanding multifunctional features of metal reinforcement such as carbon nanotubes (CNTs) have made ceramic metal composite (CMC) a wonder material, which has been proved a successful replacement of engineering alloys and MMC (metal matrix composite) [8-10]. The addition of $\mathrm{CNT}$ in the $\mathrm{SiC}$ composites as reinforced material increased its usage as a replacement of conductive material in the thermal industry, aviation and automobile industry, high-temperature region like a sensor, engine parts, etc. [11,12].

Many researchers have already investigated the effect of EDM on the surface characteristic of alloys and metal components. In the conventional machining process, the metallurgical and chemical structure of the workpiece has been changed a lot mainly due to the physical force which has been applied at its surface. But in EDM this defect minimized a lot due to the non-contact machining process. During machining in EDM, the erosion takes place by the following melting to vaporization process, at the same time as the workpiece dipped inside the di-electric solidification of that molten metal also occurred due to improper flushing. This solidified layer deposited on the upper surface of the crater which is known as heat affected zone (HAZ) or recast layer thickness (Rlt). The thickness may vary from 0.01 to $0.4 \mathrm{~mm}$ depending on the material properties and parametric condition. The Rlt/HAZ can be determined by experimental investigation but by thermal modeling, a stochastic equation has been developed to predict the HAZ [13-15]. Pandit et al. [9] has been developed a thermal model by data dependent systems (DDS) in which the transient heat transfer problem of EDM has been solved. The model also has been validated by experimental results taken in the same parameters. In Rajurkar et al. [10] the thermal modeling has been done to predict the structural characteristic (like MicroHardness, residual stress, and crack density). These characteristics are directly proportional to the HAZ.

To encounter the hitches of worldwide competitiveness, manufacturing associations are facing the problems in selecting the most ideal methods, design of process and product and equipment. To avoid these selection process complexity some optimization techniques with (MultiAttribute Decision-Making (MADM)) are being useful. MADM optimization technique stands for selecting the right decisions in the presence of many conflicting attributes which is very common in regular life $[16,17]$. A MADM problem concerns with various options to be surveyed and various criteria to evaluate the choices. MADM strategies are significant Potential instruments for analyzing complex problems related to the manufacturing industry as this process involves a capacity to predict distinctive options of parameters on various surrounding parameters. Even though a considerable amount of MADM strategies are presently available [18-20] for varying evaluation and selection issues, Multi-Objective Optimization based on Ratio Analysis (MOORA) is seen to be computationally simple and basic. Khan et al. [5] explored a unique MADM technique known as MOORA to predict the right set of parameters in the presence of different attributes.

All traditional and advanced processes are developed in order to tackle the issue of the shaping of advanced ceramics. The generation of fine shapes without microcracks is one of the main requirements of ceramic materials machining, which is very difficult to address by traditional mechanical machining methods [21,22]. Advanced machining processes can effectively overcome the disadvantages due to difference in material removal mechanisms offered by traditional machining methods. Mechanisms such as thermal material removal (EDM), mechanical material removal (abrasive jet, abrasive water jet, ultra-sonic machining), chemical (chemical machining), ionic dissolution (electro-chemical machining), etc. can be used individually or in hybrid to shape materials that are difficult to cut. Among the various advanced machining processes available, EDM is the process whose application for the machining of insulating ceramics is presented in this paper. EDM is a non-contact thermal machining process that generates regulated and spatially separated highfrequency electrical discharges to remove material from the craters that exit the workpiece. The electrical discharges take place in a dielectric fluid between the tool electrode and the workpiece electrode at the minimum distance point between the two, producing a plasma channel that enables the movement of ions and electrons between the electrodes. The electrons move to the anode and reach the anode, extracting material from the surface of it. Similar process occurs at the cathode, with ion-related material removal. The plasma temperature can be as high as $20000{ }^{\circ} \mathrm{C}$ [23]. The plasma channel breaks down after the discharge. The dielectric induces a sudden reduction in plasma temperature resulting in the implosion of the plasma channel resulting in the formation of void or vacuum and resulting in fresh dielectric flushing of the molten metal in the form of debris from the discharge zone. The debris may be hollow or solid depending on gaseous evaporation and subsequent gas evolution. Some of the advantages offered by the EDM process, which has attracted the attention of the research community, are described below. The ability to efficiently and effectively machine three-dimensional complex shapes, irrespective of the hardness of the workpiece and regardless of the product dimensions [22,24]. For example, in wire EDM processes, Gupta and Jain $[25,26]$ were able for production to produce miniaturized gears which were better than traditional miniature gear production processes. Complex form cavities can be generated by the same tool with the help of movie changes. Ziada and Koshy $[27,28]$ were capable of using the Reuleaux triangle cinematics to create regular and non-regular polygonal forms with sharp angles. Another benefit of the EDM 
process is the multifarious ways in which it can be used to change the basic configuration of the machining system. The EDM process is based on a large number of hybrid versions that make EDM more appealing. For the alloying of the surface to take place during the workmanship, Kumar [28] posed favourable machining conditions. Semiconductor industry is looking unnecessarily for some alter-natives in silicon wafers to be used in hostile environments, such as high temperature and high radiation environments where traditional semiconductors cannot function adequately [29]. Chi et al. [30] manufactured micro-spiral structural structures using the electrodissipation process in the soil. SiC scanning crystals are a useful option. Due to difficulties resulting from the very high hardness and inertness of singular silicon carbide, the costs of $\mathrm{SiC}$ single crystal-based semiconductors are therefore not easily machined and very high. EDM has recently been developed to cut wafers from silicon carbide single crystals. In slicing wafers, EDM can offer advantages, irrespectively of material hardness, since the electrical conductivity only is required. Chaudhury et al. [31] also developed the computational domain and studied the MRR of Al-SiC metal composite by considering three different types of heat fluxes.

The foregoing discussion shows the prospective for further research on the EDM of non-conductive $\mathrm{SiC}$ ceramic by adding metal reinforcement into it. Many researchers studied the Multi-Optimization of process parameters for alloys and composite. Many authors focused on the study of the physical and mechanical properties of alloys and composites. Very less work has been performed for the EDM of the MMCs and the CMCs along with the study of the physical and mechanical properties. However, till now there has been no consideration of optimization of process parameters for machining $\mathrm{SiC}$ Ceramic reinforced with CNT by EDM.

The main objective of this research is to obtain an optimal setting of process parameters by a Hybrid method of the MADM technique for EDM machining of $\mathrm{SiC}$ reinforced with CNT reinforcement. This composite has a wide application in the sensor industry, bio-medical implants, heat exchangers etc. in which accuracy and surface finish are the most important factors. In the development of quality engineering, the reduction of the variation of a product caused by several factors (mainly the environmental conditions, deterioration, and variation of the pieces) was one of the objectives, along with the mean adjusted to a specific target. To accomplish these two objectives, the concept of multi-optimization has been introduced. The main objective of multi-optimization is to of designing a process that can function properly under different conditions of use. For this reason noise factors have been considered, to obtain a set of machining parameters that can be employed for machining of $\mathrm{SiC}-4 \% \mathrm{CNT}$.

\section{Materials and experimentation}

\subsection{Material fabrication}

In the present study, an insulated silicon carbide ( $\mathrm{SiC}$ ) has been considered as the base material. $\mathrm{As} \mathrm{SiC}$ is highly

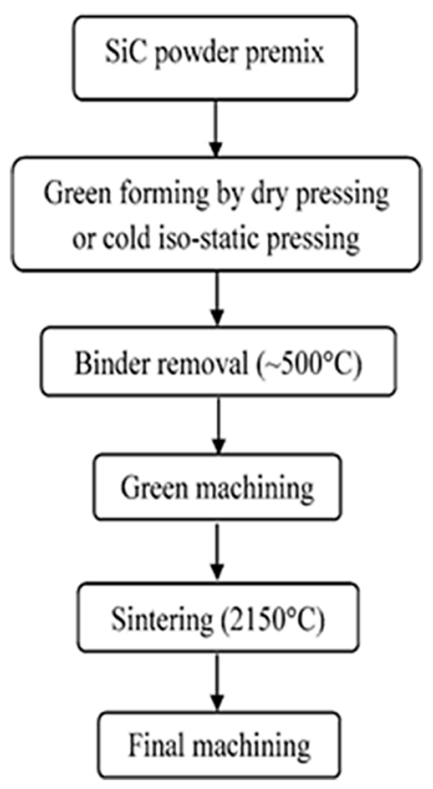

Fig. 1. Flow chart of sintering procedure of $\mathrm{SiC}$ reinforced with CNT.

electrically non-conductive material Carbon Nano Tube $(4 \% \mathrm{CNT})$ has been considered as filler material which not only improves the mechanical properties of the specimen but also helps to achieve the electrical conductivity to be machined by EDM. All the Specimens have been made from the Spark Plasma Sintering Procedure. The flow chart of step by step SPS sintering has been given in Figure 1. In the very first step of this process, $\mathrm{SiC} / \mathrm{CNT}$ s powders have to be processed followed by mixing and sonicating with the presence of isopropyl alcohol suspensions. After mixing the two solutions has to be undergone through a green compact procedure (by adding proper binder/ adhesive) at around $500^{\circ} \mathrm{C}$. In this step, all the organic volatiles has been removed and the strength has been increased to withstand the sintering process temperature. Subsequently, the SiC CMC has been sintered and get the final shape of the required dimension.

\subsection{Experimental methodology}

SMART ZNC model with a transistor circuit has been used for the EDM of $\mathrm{SiC} / 4 \%$ CNT ceramic composites. The experimentation has been performed by controlling the process parameters. In the present study, the SiC-CNT has been chosen as a workpiece material $(10 \times 10 \mathrm{~mm})$. $\mathrm{Cu}-\mathrm{W}$ rod of $(1.2 \times 15) \mathrm{mm}$ diameter has been considered as the tool material for the EDM process. Kerosene oil has been used as a dielectric fluid (with injection flushing) during the machining. Table 2 represents the material properties of the workpiece materials (three types of $\mathrm{SiC}$ ceramic composites). The values of the process parameters (peak current $(I)$, Voltage $(V)$ pulse on-time (Ton), and percentage of CNT) are illustrated in Table 3.

In Figure 2a-d the experimental set up with machining process, workpiece after machining has been shown respectively. 


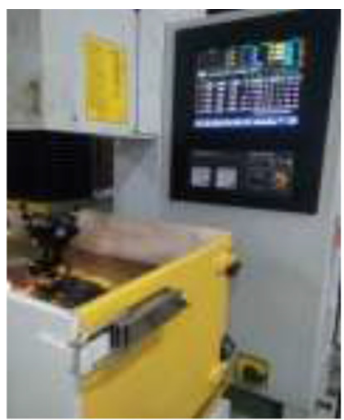

(a)

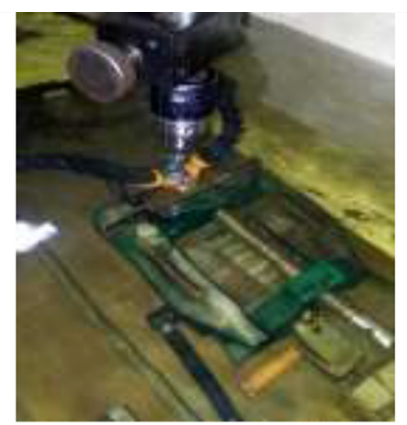

(b)

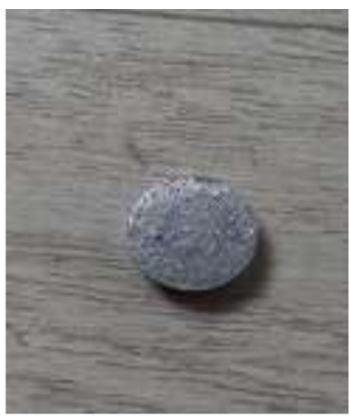

(c)

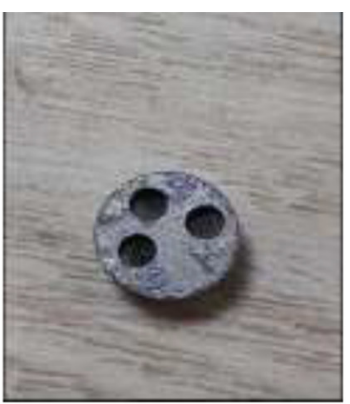

(d)

Fig. 2. (a) Die Sinking EDM Set-up. (b) Machining of SiC 6 vol\% CNT. (c) SiC 6 vol\% CNT before machining. (d) SiC 6 vol\% CNT after machining.

Table 1. Process parameters with levels.

\begin{tabular}{|c|c|c|c|c|c|}
\hline \multirow[t]{2}{*}{ Parameters } & \multirow[t]{2}{*}{ Symbols } & \multicolumn{3}{|c|}{ Levels } & \multirow{2}{*}{ unit } \\
\hline & & $\mathrm{I}$ & II & III & \\
\hline Peak current & Ip & 1 & 2 & 3 & Amp \\
\hline Gap voltage & $\mathrm{Vg}$ & 30 & 50 & 70 & $\mathrm{~V}$ \\
\hline Pulse on time & Ton & 50 & 100 & 150 & $\mu \mathrm{S}$ \\
\hline Duty cycle & Dc & 5 & 7 & 9 & $\%$ \\
\hline Polarity & $\mathrm{P}$ & $-/+$ & & & \\
\hline \multicolumn{6}{|l|}{ Fixed parameters } \\
\hline Flushing pressure & $\mathrm{Fp}$ & 0.5 & & & $\mathrm{Kgf} / \mathrm{cm}^{2}$ \\
\hline Working time & $\mathrm{WT}$ & 10 & & & $\min$ \\
\hline Servo sensitivity & SEN & 9 & & & \\
\hline Arc sensitivity & ASEN & 9 & & & \\
\hline \multicolumn{6}{|c|}{ Dimension of electrodes } \\
\hline Work piece & $10 \mathrm{~mm} \times 5 \mathrm{~mm}$ & & & & \\
\hline Tool electrode & $2 \mathrm{~mm} \times 10 \mathrm{~mm}$ & & & & \\
\hline
\end{tabular}

\subsection{Design of experimentation (DOE)}

Mathematical modelling is a technique of establishing the relationship between the process parameters and the performance measures and selecting an optimum condition for the process. DOE is one of the best mathematical modeling tools which is being used to analyze the effect of process parameters for various machining problems. In this study, DOE has been used by MINITAB software to design the EDM process by considering four well-regulated process variables i.e. peak current $(I)$, Voltage $(V)$, Pulse-On time (Ton), duty factor (Dc). A new hybrid technique which is the combination of two established methods i.e MOORA and WPCA has been used for this study. Both MOORA and WPCA are an effective tool for designing and optimizing the process by analyzing several machining parameters and evaluates their compound interactions for the effect of performance measures. The brief discussion of the hybrid coupling method has been presented in the following section.
Taguchi $\mathrm{L}_{27}$ orthogonal array has been designed by keeping the above-selected input parameters as variables. The experiment has been carried out according to the $\mathrm{L}_{27}$ array design of a set of parameters (Tab. 1) for this set of experiments by EDM. Table 2 represents the $\mathrm{L}_{27}$ orthogonal array for $\mathrm{SiC} 4 \mathrm{vol} \% \mathrm{CNT}$ machining.

\section{Methodology}

The following performance measure has been calculated from the experimental analysis of $\mathrm{Be}-\mathrm{Cu}$ alloy machined by EDM.

- Material removal rate (MRR): It is defined as the material removal per minute of the period or the rate at which loss of material takes place from the workpiece surface.

MRR has been calculated from equation (1)

$$
\operatorname{MRR}=\left(W_{i}-W_{f}\right) /(t \times \rho) \mathrm{mm}^{3} / \mathrm{min}
$$


Table 2. $\mathrm{L}_{27}$ orthogonal array of design of experiments.

\begin{tabular}{|c|c|c|c|c|}
\hline $\begin{array}{l}\text { Run } \\
\text { No. }\end{array}$ & $\begin{array}{l}\text { Current } \\
(A)\end{array}$ & $\begin{array}{l}\text { Voltage } \\
(V)\end{array}$ & $\begin{array}{l}\text { Pulse-On } \\
\text { (Ton) }\end{array}$ & $\begin{array}{l}\text { Duty cycle } \\
\left(D_{C}\right)\end{array}$ \\
\hline 1 & 1 & 30 & 50 & 5 \\
\hline 2 & 1 & 30 & 100 & 7 \\
\hline 3 & 1 & 30 & 150 & 9 \\
\hline 4 & 1 & 50 & 50 & 7 \\
\hline 5 & 1 & 50 & 100 & 9 \\
\hline 6 & 1 & 50 & 150 & 5 \\
\hline 7 & 1 & 70 & 50 & 9 \\
\hline 8 & 1 & 70 & 100 & 5 \\
\hline 9 & 1 & 70 & 150 & 7 \\
\hline 10 & 2 & 30 & 50 & 7 \\
\hline 11 & 2 & 30 & 100 & 9 \\
\hline 12 & 2 & 30 & 150 & 5 \\
\hline 13 & 2 & 50 & 50 & 9 \\
\hline 14 & 2 & 50 & 100 & 5 \\
\hline 15 & 2 & 50 & 150 & 7 \\
\hline 16 & 2 & 70 & 50 & 5 \\
\hline 17 & 2 & 70 & 100 & 7 \\
\hline 18 & 2 & 70 & 150 & 9 \\
\hline 19 & 3 & 30 & 50 & 9 \\
\hline 20 & 3 & 30 & 100 & 5 \\
\hline 21 & 3 & 30 & 150 & 7 \\
\hline 22 & 3 & 50 & 50 & 5 \\
\hline 23 & 3 & 50 & 100 & 7 \\
\hline 24 & 3 & 50 & 150 & 9 \\
\hline 25 & 3 & 70 & 50 & 7 \\
\hline 26 & 3 & 70 & 100 & 9 \\
\hline 27 & 3 & 70 & 150 & 5 \\
\hline
\end{tabular}

where, initial and final weights $(\mathrm{kg})$ are $W_{i}$ and $W_{f}$ of the workpiece, respectively; the machining time (in min) is $t$, and the density of the workpiece is $\rho(\mathrm{g} / \mathrm{cc})$.

- Tool wear rate (TWR): It can be defined as the rate of material removal or the rate at which loss of material takes place from the tool.

$$
\mathrm{TWR}=W_{t i}-W_{t f} /\left(t \times \rho_{t}\right) \mathrm{mm}^{3} / \mathrm{min}
$$

where initial and final weights $(\mathrm{kg})$ are $W_{t i}$ and $W_{t f}$ of the workpiece, respectively; the machining time (in min) is $t$ and density of the workpiece material $\rho_{t}(\mathrm{~g} / \mathrm{cc})$.

- Surface roughness: It is also known as arithmetic average roughness ( $\mathrm{Ra}$ ), which means the arithmetic mean of the heights of machined surface irregularities concerning the mean line, for a fixed sampling length. The surface roughness ( $\mathrm{Ra}$ value) of the machined surface is measured with portable stylus type profilo meter, Talysurf model.

- White layer thickness: The recast layer is produced by quenching of evaporated or melted material in dielectrics in the EDMed surface. The top section of the white layer is a porous structure.
- Over cut: It is defined as the difference between the actual tool diameter and diameter of the crater after machining.

\subsection{Weighted principal component analysis (WPCA)}

In the PCA method, the standardization has to be done for each response for calculating the multi-response performance characteristic. The basic principle involves the transformation of quality loss into a multi-response problem is based on Pearson and Hotelling to enlighten the arrangement of variance co-variance in a linear combination of each response into normalizes value. This paper represents an advanced PCA technique by adding weightage to the corresponding parameters. In this method, each parameter has been assigned by its weighting percentage. By doing this the effect of each input parameter remains constant during the multi optimization decision making process. The very first step after normalization is to calculate Pearson relation co-efficient by using Equation (3).

$$
R_{j l}=\left[\frac{\operatorname{Cov}\left(x_{i}(j), x_{i}(l)\right.}{\sigma x_{i}(j)^{*} \sigma x_{i}(l)}\right]
$$

where $x_{i}(j)$ is the normalized values of individual responses, $\operatorname{Cov}\left(x_{i}(j), x_{i}(l)\right)$ is the covariance of response variables $j$ and $l, \sigma x_{i}(j)$, and $\sigma x_{i}(l)$ is the standard deviation of response variables $j$ and $l$. Subsequently, Eigenvalues and corresponding eigenvectors are

$$
\left(R-\lambda_{x} I_{m}\right) V_{i k}=0
$$

where $\lambda_{x}$ is the Eigenvalues

$$
\sum_{i=1}^{n} \lambda_{k}=n \text { and } V_{i k}=\left[\begin{array}{lll}
a k_{1} & a k_{2}, a k_{3} \ldots \ldots . . . a k m
\end{array}\right]^{T} \text { are the }
$$

Eigenvectors corresponding to Eigenvalue $\lambda_{k}$. Thus, the principal components are

$$
y_{m k}=\sum_{i=1}^{n} x_{m}(i) V_{i k}
$$

where, $Y_{m k}$ represents a series of principal components i.e $Y_{m_{1}}, Y_{m_{2}}, \ldots, Y_{m k}$

The principle components have to be arranged according to descending order as per its variance. The variance of each component is known to be its weight. After normalizing the data the Eigenvalues and vectors have to be calculated followed by its multiple performance index (MPI). The highest MPI resembles the optimal set of process parameters.

\subsection{Multi-Objective Optimization based on Ratio Analysis (MOORA)}

To overcome the difficulties of today's manufacturing industries for selecting an optimum condition differently. Multi-Attribute Decision-making methods (MADM) has to be used. These MADM methods are more reliable in the 
presence of Conflicting attributes which are common in regular life. The MADM strategy helps judge the distinctive option concerning the change in different criteria. Different MADM Strategies are used to evaluate an optimal condition for a selective issue.

But Multi-Objective Optimization based on Ratio Analysis (MOORA) is a simple and convenient method to analyze different input parameters in the presence of certain constraints. Initially, it has been applied by Brauers (2004) for the Optimization of Process Parameter. From the survey also it can be concluded that MOORA is a time shaving, accurate decision-making method to get an Optimum condition.

\subsection{Combined MOORA coupled with WPCA (hybrid optimization)}

MOORA is a robust optimization technique that can optimize two or more than two variables with certain constraints. On the other hand, WPCA is a Statistical way to optimize the multivariable attribute by considering the weightage of each parameter. By combining these two multi-attribute technique the result can be more realistic. The necessary steps for MOORA Coupled PCA are described below.

Step 1 Defining Objective of the Problem.

Step 2 Develop the Decision Matrix which represents each variable in a matrix form with their levels.

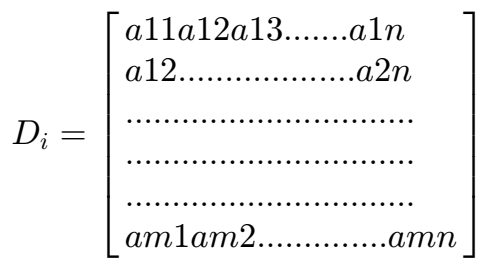

where $a_{i j}$ is the performance measure of the $i$ th alternative on $j$ th attribute, $\mathrm{m}$ is the number of alternatives, and $n$ is the number of attributes.

Step 3 Normalizing the Process parameters by the following Normalization formula. This method involves the conversion of the attributes to a non-dimensional number by ratio system which is the square root of the sum of squares of individual alternative per criterion.

$$
a_{i j}^{*}=\left[\frac{a_{i j}}{\sqrt{\sum_{i=1}^{m} a_{i j}^{2}}}\right]
$$

where $a_{i j}^{*}$ represents the normalized value at the $i$ th alternative on the $j$ th criterion which lies between 0 and 1 .

Step 4 In WPCA after Normalization of attributes Principal Component of each parameter is being calculated according to their Eigenvalues. But in MOORA-WPCA Overall assessment value has to be calculated by considering their weightage. As some parameters are quite influential than other parameters. In this case, the weightage value has to be multiplied by the number. The following formula has been used to calculate the
Overall assessment value.

$$
Y_{i}=\sum_{j=1}^{g} w_{j} a_{i j}^{*}-\sum_{j=g+1}^{n} w_{j} a_{i j}^{*}
$$

where $w_{j}$ is known as the weight of the $j$ th criterion.

Step 5 Among the entire calculated Overall assessment value rank has to be given according to the higher to lower trend. The highest number of rank represents the best optimal array of parameters whereas the lowest number represents the worst condition of input parameters.

Step 6 For checking the credibility of the Optimum condition, a confirmative test has been carried out by experimenting with a given set of parameters.

\section{Results \& discussion}

In the present study, the machining performance of EDM for $\mathrm{SiC} 4 \mathrm{vol} \% \mathrm{CNT}$ has been studied. Taguchi $\mathrm{L}_{27}$ orthogonal array has been designed by MINITAB. MRR, PFE, SR, and Rlt have been considered as output parameters. In this study, three different MADM optimization techniques have been used to select the best optimum condition for CMC. The First MOORA technique has been used to get the best set of machining parameters for optimum process parameters. In the next step, WPCA has been carried out to overcome the hitches which already mentioned in the previous section of MOORA. Finally, a combined method has been incorporated for getting the optimum set of input parameters. A comparison between all three MADM has been carried out.

\subsection{Mathematical modelling}

In this section different step of Hybrid MOORA-WPCA has been presented. In Table 3 the experimental finding has been presented for different run according to $\mathrm{L}_{27}$ orthogonal array. In Table 4 the decision matrix along with the normalized value of each parameter has been represented for the $\mathrm{Cu}-\mathrm{W}$ electrode by incorporating step 7 of the previous section. After normalization, the Proportionality percentage of each factor has been calculated this has been represented in Table 5 as given in step 8. In Table 6 the contribution factor has been calculated by squaring the high proportional Eigenvalue as given in step 1. The contribution factor for MRR, PFE, $\mathrm{SR}$, and Rlt is $0.637,0.022,0.336$, and 0.005 respectively. By converting all the input parameters to a dimensionless number (normalizing factor i.e (Normalized MRR) NMRR, (Normalized PFE) NPFE, (Normalized SR) NSR and (Normalized Rlt) NRlt has been evaluated. Finally, the overall assessment value $\left(Y_{i}\right)$ has been calculated which has been represented in Table 7 . The highest value of $Y_{i}$ i.e 0.156232 has been assigned rank 1 which resembles the 21 rows of $\mathrm{L}_{27}$ design. The optimum parameters according to MOORA-PCA are A3B1C3D2 i.e. when the current is at $3 \mathrm{~A}$, voltage is at $30 \mathrm{~V}$, pulse-on time is $150 \mu \mathrm{S}$, and duty cycle is $70 \%$. 
Table 3. Experimental results (Decision Matrix).

\begin{tabular}{lllll}
\hline Run No. & MRR & PFE & Rlt & SR \\
\hline 1 & 0.16165 & 32 & 0.4352 & 0.12 \\
2 & 0.18472 & 37.42 & 0.5005 & 0.13 \\
3 & 0.16919 & 42.44 & 0.5832 & 0.18 \\
4 & 0.44324 & 33.43 & 0.759 & 0.36 \\
5 & 0.61976 & 43.5 & 0.873377 & 0.37 \\
6 & 0.68714 & 47 & 0.9156 & 0.4 \\
7 & 1.03758 & 47.8 & 0.8352 & 0.55 \\
8 & 1.37164 & 58.7 & 0.7434 & 0.77 \\
9 & 1.06481 & 58.99 & 1.224 & 1.13 \\
10 & 1.22939 & 63.34 & 1.1184 & 1.21 \\
11 & 1.54538 & 67.52 & 1.157801 & 1.23 \\
12 & 2.66744 & 70.12 & 0.76075 & 1.44 \\
13 & 1.68146 & 61.34 & 1.15758 & 1.324 \\
14 & 2.09089 & 64.1 & 1.44 \\
15 & 2.86124 & 68.45 & 0.9702 & 1.76 \\
16 & 3.373203 & 65.66 & 1.156 & 1.77 \\
17 & 4.154434 & 0.946 & 1.82 \\
18 & 2.744265 & 65.22 & 1.91 \\
19 & 2.574495 & 74.31 & 0.8064 & 1.94 \\
20 & 2.66199 & 2.33472 & 2.01 \\
21 & 2.6599936 & 2.32646 & 2.11 \\
22 & 2.85260745 & 2.5233 & 2.21 \\
23 & 2.78889368 & 73.86 & 2.584 & 2.24 \\
24 & 3.3775638 & 73.21 & 2.384826 & 2.27 \\
25 & 4.83385695 & 2.527525 & 2.35 \\
26 & 4.38932833 & 2.52175 & 2.35 \\
27 & 6.33651777 & 1.58179 & 2.4 \\
\hline & & 2.06804 & 1.242376 & \\
\end{tabular}

Table 4. Normalization table (normalized output parameter).

\begin{tabular}{|c|c|c|c|c|}
\hline $\begin{array}{l}\text { Run } \\
\text { No. }\end{array}$ & NMRR & NPFE & NRlt & NSR \\
\hline 1 & 0.011468 & 0.095562 & 0.054104 & 0.014462 \\
\hline 2 & 0.013104 & 0.111748 & 0.062222 & 0.015668 \\
\hline 3 & 0.012003 & 0.12674 & 0.072503 & 0.021694 \\
\hline 4 & 0.031444 & 0.099833 & 0.094358 & 0.043387 \\
\hline 5 & 0.043967 & 0.129905 & 0.108577 & 0.044593 \\
\hline 6 & 0.048747 & 0.140357 & 0.113826 & 0.048208 \\
\hline 7 & 0.073608 & 0.142746 & 0.103831 & 0.066286 \\
\hline 8 & 0.097306 & 0.175297 & 0.092419 & 0.092801 \\
\hline 9 & 0.075539 & 0.176163 & 0.152166 & 0.136188 \\
\hline 10 & 0.087215 & 0.189154 & 0.139038 & 0.14583 \\
\hline 11 & 0.109632 & 0.201637 & 0.143936 & 0.14824 \\
\hline 12 & 0.189233 & 0.209401 & 0.094576 & 0.173549 \\
\hline 13 & 0.119286 & 0.183181 & 0.143909 & 0.159569 \\
\hline 14 & 0.148331 & 0.191423 & 0.120614 & 0.173549 \\
\hline 15 & 0.202981 & 0.204414 & 0.143713 & 0.212116 \\
\hline 16 & 0.239301 & 0.196082 & 0.117606 & 0.213321 \\
\hline
\end{tabular}


Table 4. (continued).

\begin{tabular}{|c|c|c|c|c|}
\hline $\begin{array}{l}\text { Run } \\
\text { No. }\end{array}$ & NMRR & NPFE & NRlt & NSR \\
\hline 17 & 0.294722 & 0.191125 & 0.100251 & 0.219347 \\
\hline 18 & 0.194683 & 0.194768 & 0.29025 & 0.230194 \\
\hline 19 & 0.182639 & 0.221914 & 0.289223 & 0.233809 \\
\hline 20 & 0.188846 & 0.223138 & 0.313694 & 0.242246 \\
\hline 21 & 0.188704 & 0.232515 & 0.32124 & 0.254298 \\
\hline 22 & 0.202369 & 0.218629 & 0.296479 & 0.26635 \\
\hline 23 & 0.197849 & 0.222989 & 0.314219 & 0.269966 \\
\hline 24 & 0.23961 & 0.234277 & 0.313501 & 0.273581 \\
\hline 25 & 0.342922 & 0.239593 & 0.196646 & 0.283223 \\
\hline 26 & 0.311386 & 0.245894 & 0.257096 & 0.283223 \\
\hline 27 & 0.449523 & 0.255211 & 0.154451 & 0.289249 \\
\hline
\end{tabular}

Table 5. Eigen value and proportion of principal component.

\begin{tabular}{llll}
\hline S. No. & Principal component & Eigen values & Proportion (\%) \\
\hline 1 & 1st & 3.3463 & 0.637 \\
2 & 2nd & 0.5450 & 0.022 \\
3 & 3rd & 0.0878 & 0.336 \\
4 & 4th & 0.0209 & 0.005 \\
\hline
\end{tabular}

Table 6. Eigen vectors for principal component.

\begin{tabular}{|c|c|c|c|c|c|c|}
\hline \multirow{2}{*}{$\frac{\text { S. No }}{1}$} & \multirow{2}{*}{$\frac{\text { Variables }}{\text { MRR }}$} & \multicolumn{4}{|c|}{ Eigen vectors } & \multirow{2}{*}{$\frac{\text { Contribution }}{0.837}$} \\
\hline & & 0.486 & 0.577 & -0.550 & 0.358 & \\
\hline 2 & $\mathrm{PDF}$ & 0.530 & 0.098 & 0.779 & 0.321 & 0.935 \\
\hline 3 & Rlt & 0.435 & -0.810 & -0.299 & 0.255 & 0.973 \\
\hline 4 & SR & 0.532 & 0.038 & -0.028 & -0.839 & 1.000 \\
\hline
\end{tabular}

Table 7. Overall Assessment Value.

\begin{tabular}{lll}
\hline Run No. & Yi & Rank \\
\hline 1 & 0.038621 & \\
2 & 0.044671 & \\
3 & 0.052858 \\
4 & 0.051217 \\
5 & 0.059751 & \\
6 & 0.063613 & \\
7 & 0.061832 & \\
8 & 0.071007 & \\
9 & 0.100443 & \\
10 & 0.101682 & \\
11 & 0.101529 & \\
12 & 0.083003 & \\
13 & 0.097388 & \\
14 & 0.092541
\end{tabular}

Table 7. (continued).

\begin{tabular}{lll}
\hline Run No. & Yi & Rank \\
\hline 15 & 0.098983 & \\
16 & 0.083478 & \\
17 & 0.067481 & \\
18 & 0.131272 & \\
19 & 0.14261 & 1 \\
20 & 0.148597 & \\
21 & 0.156232 & \\
22 & 0.147959 & \\
23 & 0.154671 & \\
24 & 0.148904 & \\
25 & 0.106716 & \\
26 & 0.127373 & \\
27 & 0.07971 & \\
\hline
\end{tabular}




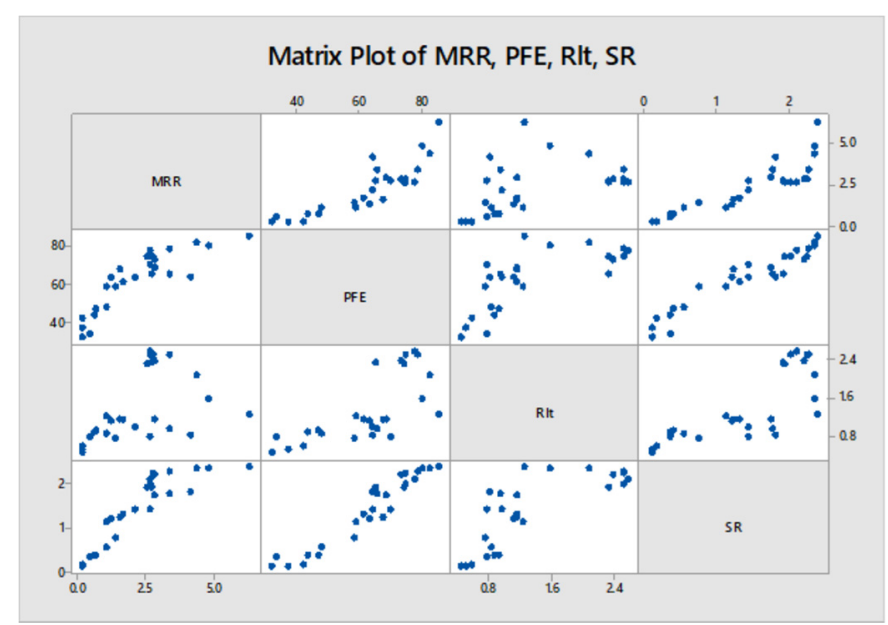

Fig. 3. Matrix Plot for $\mathrm{L}_{27}$ orthogonal array Data set matrix plot.
Figure 3 shows the matrix plot of $\mathrm{L}_{27}$ orthogonal array which has been done by Minitab Software. The matrix scatters plot indicates the relationship between two variables by the dot. This gives an idea about the structured relationship in two dimensions.

Figure 4a-d shows the residual plots for the four output parameters i.e MRR PFE, Rlt \& SR respectively. Figure 4a shows the residual plot for MRR which showing the highest for an increase in current and pulse-on time. For all residual plot analyses the $\mathrm{R}_{\text {adj }}$ showing average of $96.4 \%$.

Figure 5a-d shows the main effect plot for the output parameters. With an increase in current, all the parameters significantly increase but increasing voltage Rlt slightly decreases due to an increase in PFE. Similarly, by increasing the Duty Cycle the SR also decreases. From the interaction plot in Figure 6a-d it has been clearly shown that the most interacting input parameters are current, pulse-on, and voltage.

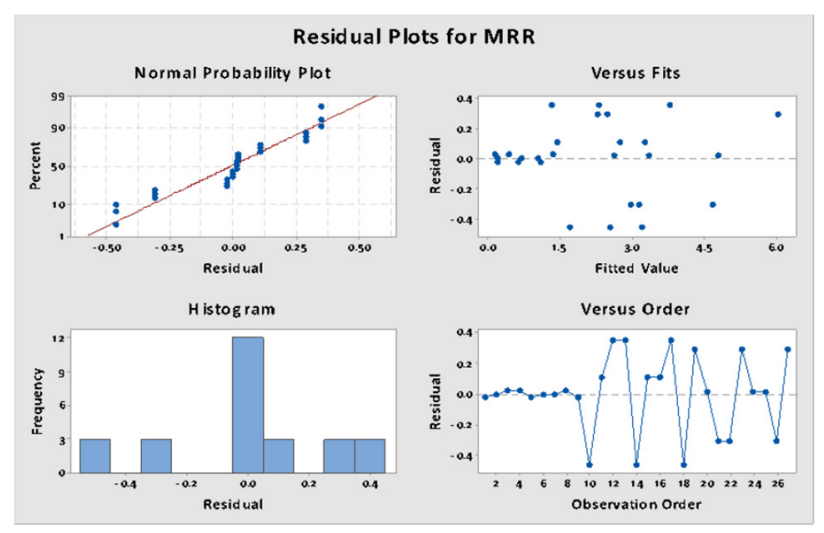

(a)

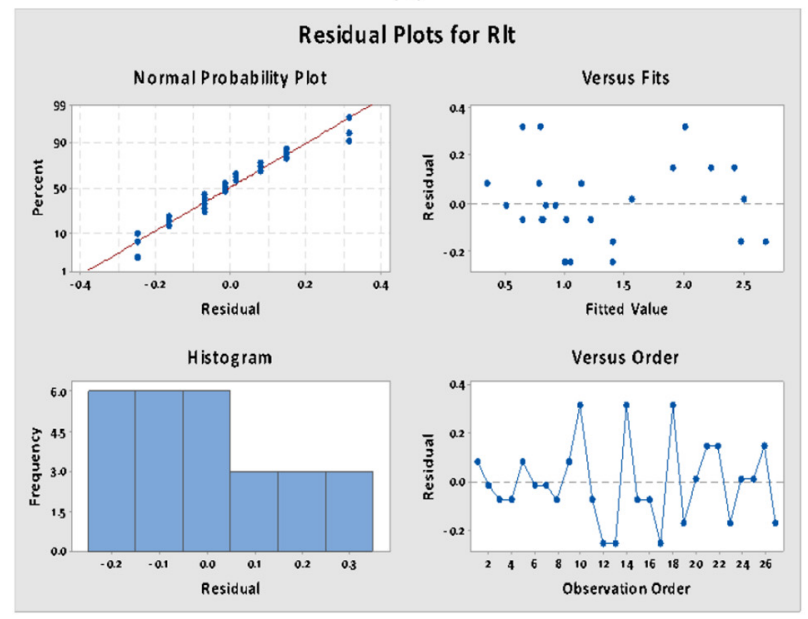

(c)

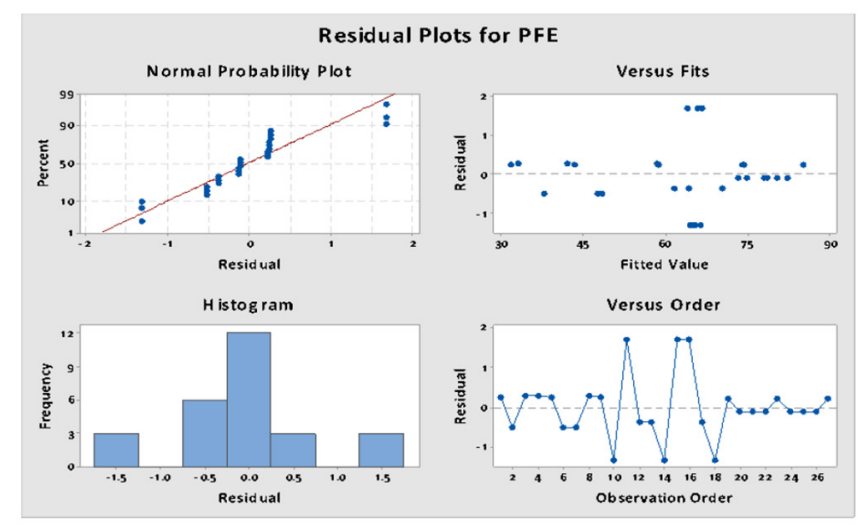

(b)

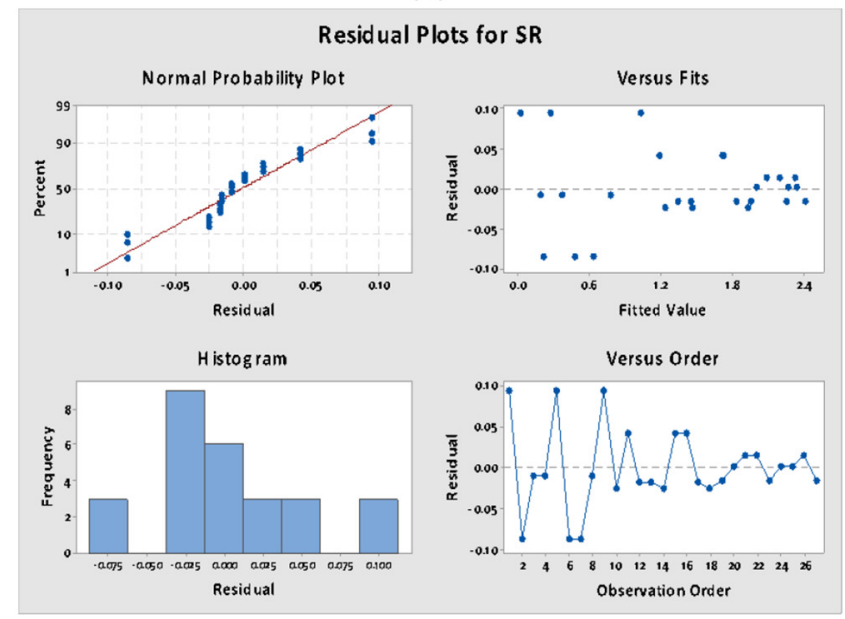

(d)

Fig. 4. (a)-(d) Residual plots for MRR, PFE, Rlt and SR respectively. 


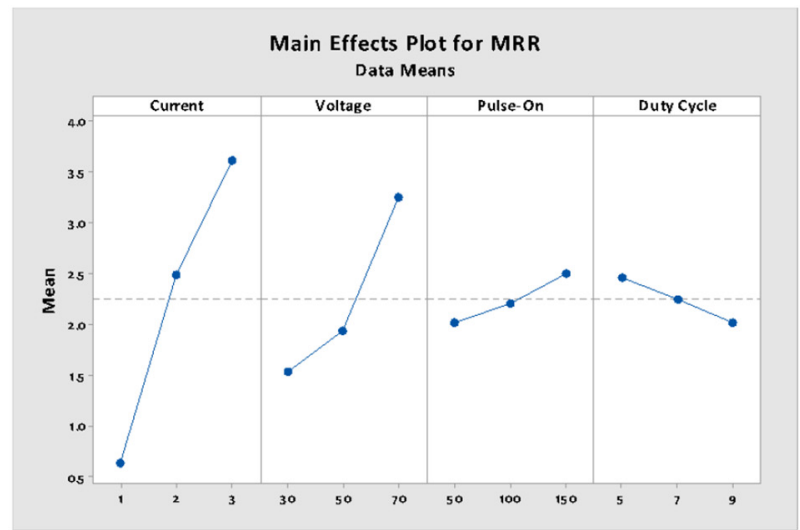

(a)

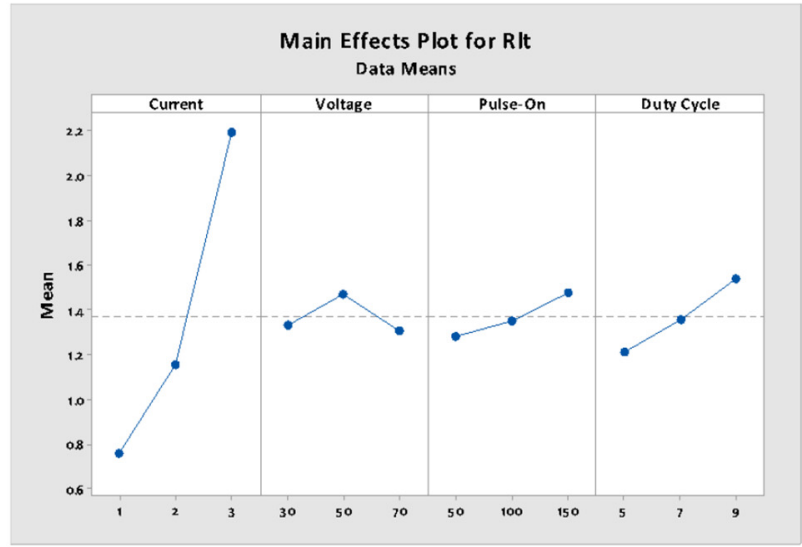

(c)

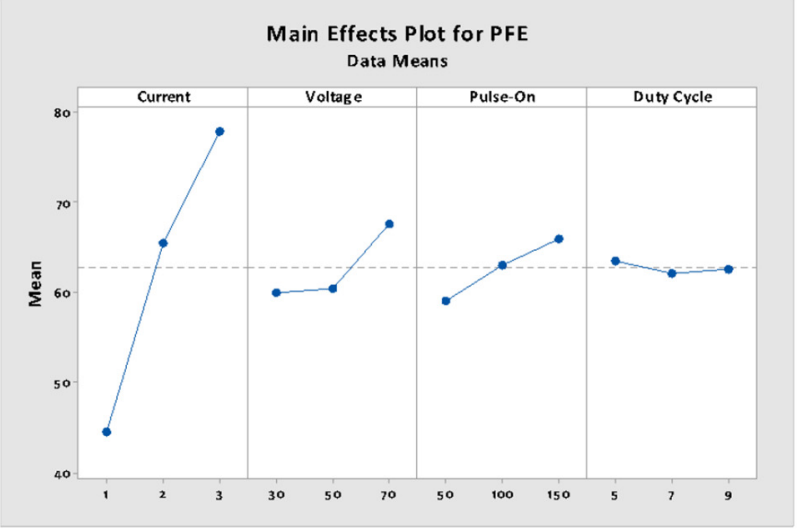

(b)

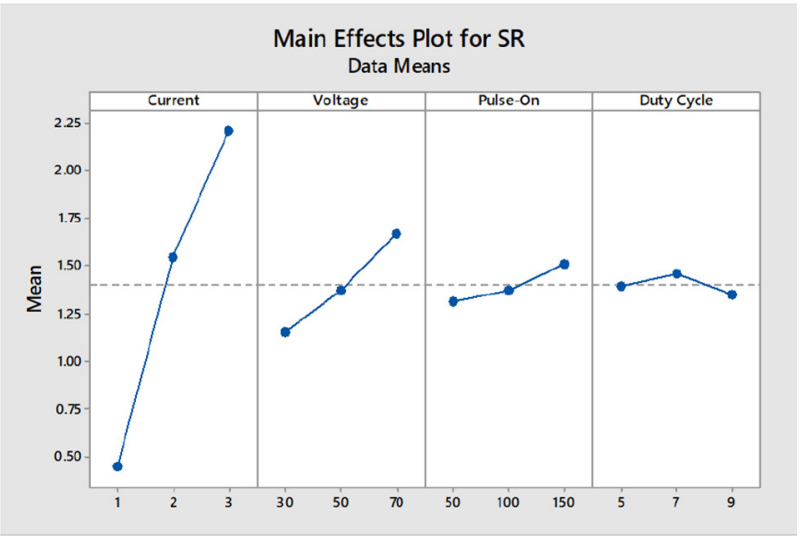

(d)

Fig. 5. (a)-(d) Main Effects plot for MRR, PFE, Rlt and SR respectively.

Table 8. Optimum condition.

\begin{tabular}{llc}
\hline Process parameters & Optimal condition & Error (\%) \\
\hline MOORA & $\mathrm{A}_{1} \mathrm{~B}_{3} \mathrm{C}_{1} \mathrm{D}_{2}$ & 11.2 \\
WPCA & $\mathrm{A}_{3} \mathrm{~B}_{3} \mathrm{C}_{3} \mathrm{D}_{2}$ & 12.4 \\
MOORA/PCA & $\mathrm{A}_{3} \mathrm{~B}_{1} \mathrm{C}_{3} \mathrm{D}_{2}$ & 5.6 \\
\hline
\end{tabular}

\subsection{Confirmative tests}

Three optimal conditions have been obtained from three different MADM techniques. In MOORA optimization the optimum condition has been changed to $\mathrm{A}_{1} \mathrm{~B}_{3} \mathrm{C}_{1} \mathrm{D}_{2}$. By applying weighted PCA (WPCA) the optimum set of input parameters is $\mathrm{A}_{1} \mathrm{~B}_{2} \mathrm{C}_{2} \mathrm{D}_{2}$. Table 8 represents a comparative study of the three models (MOORA, WPCA \& MOORA-WPCA) along with the Optimum condition for $\mathrm{SiC}$ (4 vol\% CNT) Ceramic. The Error percentage is highest in the model whereas it is lowest in MOORA-WPCA. The Predicted MRR of EDM of $\mathrm{SiC}$ (4 vol\% CNT) optimized by MOORAWPCA is $2.66 \mathrm{~mm}^{3} / \mathrm{min}$ and the experimental result is $2.51 \mathrm{~mm}^{3} / \mathrm{min}$.
Figure $7 \mathrm{a}-\mathrm{c}$ is the morphology of the crater surface of the experimental value of MRR at the optimized set of input parameters and the presence of the CNT in the workpiece surface.

\section{Conclusion}

In this study, the EDM of Nonconductive ceramic SiC Composite reinforced with 4 vol\% CNT has been performed by considering the $\mathrm{Cu}-\mathrm{W}$ tool. The experimental results have been found out by considering the Taguchi $\mathrm{L}_{27}$ orthogonal array design. Three different optimized conditions have been found out by considering a Multi variant hybrid optimized method (MOORA Coupled WPCA). 


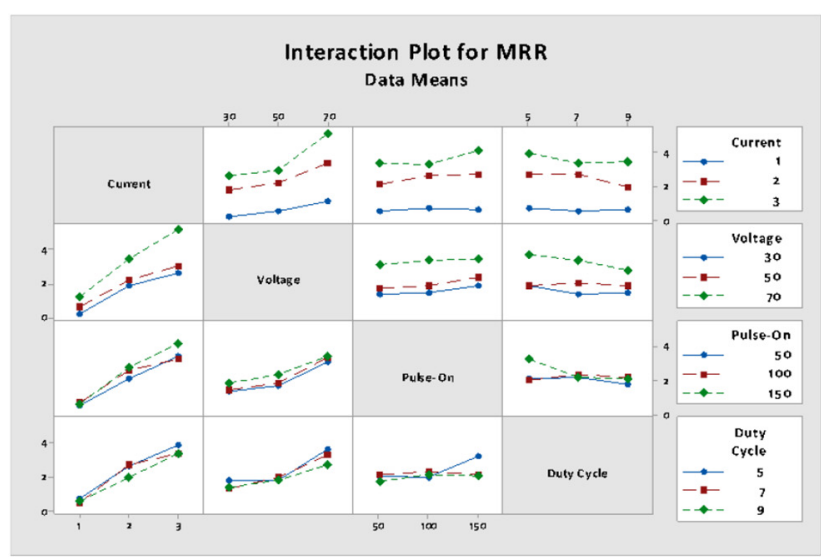

(a)

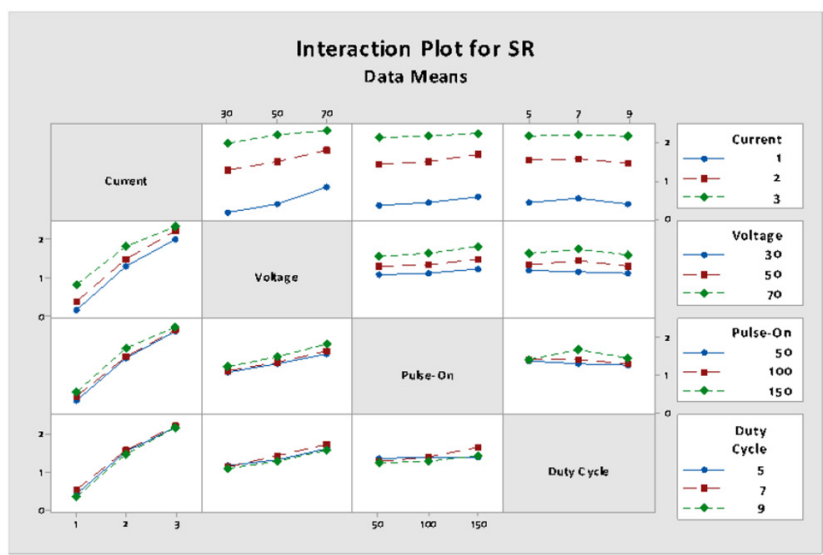

(c)

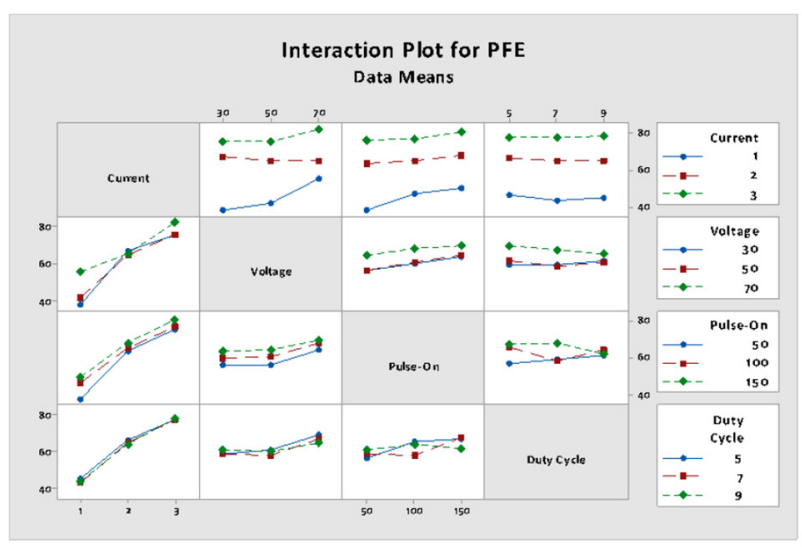

(b)

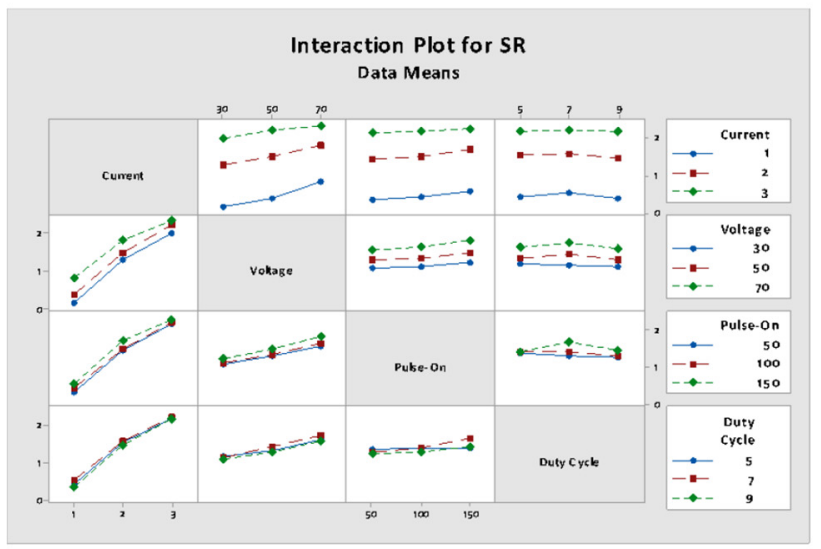

(d)

Fig. 6. (a)-(d) Interaction Plot for MRR, PFE, Rlt and SR.

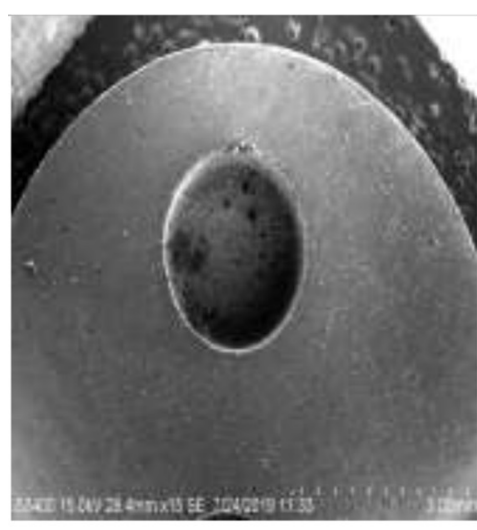

(a)

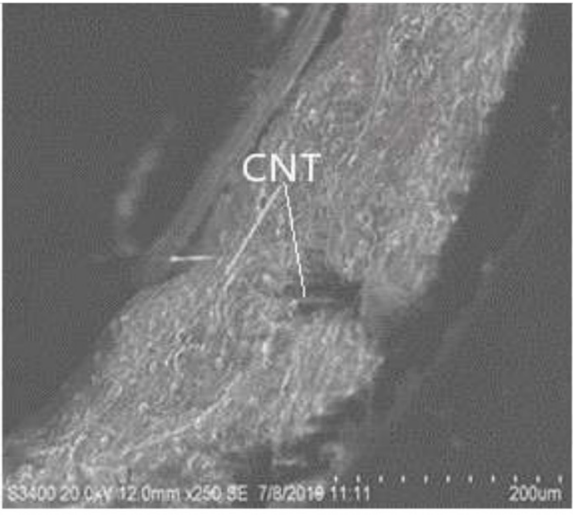

(b)

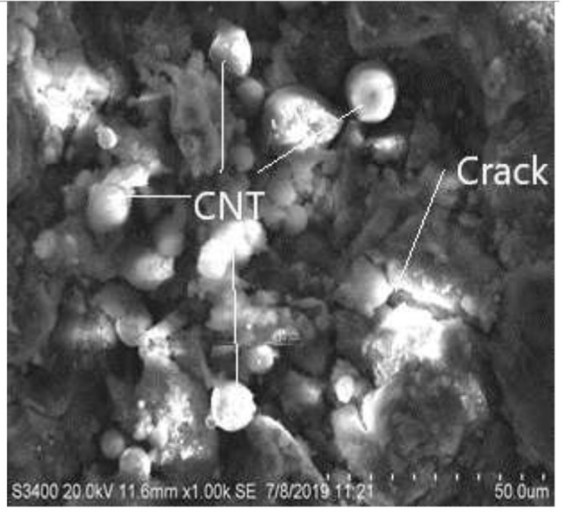

(c)

Fig. 7. (a) Machined Surface of SiC-4\% CNT by EDM (Optimized Condition obtained from MOORA/PCA). (b) SEM image of CNT in the machined surface. (c) Crack surface of SiC after machining.

Based on the compared results of optimization and performance analysis of different output parameters with significant input process parameters the following conclusion has been made.

- The adaptive Multi variant approach MOORA-PCA is proved to be more supportive technique that restricts the limitation of the decision making process for EDM process.

- In this study, three different combined decision-making process (WPCA, MOORA-PCA, and Predicted
Optimization) has been compared. The least error between the experimental result and the optimized condition (MOORA-PCA) is around 5.4\% obtained for the $\mathrm{Cu}-\mathrm{W}$ tool electrode machined surface.

By machining the $\mathrm{SiC}$ through the $\mathrm{Cu}-\mathrm{W}$ tool it gives the highest Material removal rate $\left(2.6 \mathrm{~mm}^{3} / \mathrm{min}\right)$ at $3 \mathrm{~A}$ current. Similarly, the highest PFE achieved is $78 \%$, the lowest Recast layer of $2.56 \mu \mathrm{m}$ and Surface roughness of $2 \mu \mathrm{m}$ for $3 \mathrm{~A}$ current, $30 \mathrm{~V}$ voltage, and $150 \mu \mathrm{S}$ pulse-On time. 
- The removal rate increases with an increase in CNT proportion within the $\mathrm{SiC}$ composites but surface roughness decreases with CNT proportion.

- For automobile applications, heat exchanger and water filtration application, where presized dimension is the most required the $\mathrm{SiC}$ composite (4\% by vol of CNT reinforced) machined by EDM can be considered.

- Finally, we can wrap off the study by concluding that the used Multi-objective optimized model has a significant effect on choosing the process input variables on any modern machining process.

\section{References}

1. M. Kunieda, B. Lauwers, K.P. Rajurkar, B.M. Schumacher, Advancing EDM through fundamental insight into the process, CIRP Ann. Manufactur. Technol. 54 (2005) 64-87

2. H. Majumder, K.P. Maity, J. Adv. Manuf. Syst. 168 (2017) $1-99$

3. Y. Yildiz, M. Sundaram, K.P. Rajurkar, M. Nalbant, The Effects of Cold and Cryogenic Treatments on the Machinability of Beryllium-Copper Alloy in Electro Discharge Machining Industrial and Management Systems Engineering Faculty Publications 74 (2011)

4. P. Chaudhury, S. Samantaray, Electro thermal modelling of electrical discharge machining of $\mathrm{Be}-\mathrm{Cu}$ alloy by varying fraction of energy. Annales de Chimie-Science des Matériaux, Vol. 43, No. 4, pp. 273-279 (2019)

5. A. Khan, K. Maity, Application of MCDM-based TOPSIS method for the optimization of multi-quality characteristics of modern manufacturing processes, Int. J. Eng. Res. Africa 23 (2016) 24-32

6. A. Khan, K. Maity, Application of MCDM-based TOPSIS method for the optimization of multi-quality characteristics of modern manufacturing processes, Int. J. Eng. Res. Africa 23 (2016) 33-51

7. J.D. Patel, K.D. Maniya, Application of AHP/MOORA method to select wire cut electrical discharge machining process parameter to cut EN31 alloys steel with brass wire, Mater. Today Proc. 2 (2015) 2496-2503

8. S. Dong, Z. Wang, Y. Wang, H. Liu, An experimental investigation of enhancement surface quality of micro-holes for $\mathrm{SiC} 4$ vol\% CNTs using micro-EDM with multi-diameter electrode and different dielectrics, Proc. CIRP 42 (2016) 257-262

9. K.P. Rajurkar, W.M. Wang, R.P. Lindsay, Real-time stochastic model and control of EDM, CIRP Annals 39 (1990) 187-190

10. K.P. Rajurkar, S.M. Pandit, Adaptive control of EDM technology and research, in Manufacturing Engineering Transactions. Dearborn, MI, USA SME, North American Manufacturing Research Inst., 1985, pp. 8-14

11. S. Li, X. Xiong, Multi-response robust design based on principal component and grey relational analysis, 2014 11th World Congress on Intelligent Control and Automation (WCICA) (2014) 5024-5029
12. A.P. Paiva, J.R. Ferreira, P.P. Balestrassi, A multivariate hybrid approach applied to AISI 52100 hardened steel turning optimization, J. Mater. Process. Technol. 189 (2007) $26-35$

13. I. Portnoy, K. Melendez, H. Pinzon, M. Sanjuan, An improved weighted recursive PCA algorithm for adaptive fault detection, Control Eng. Pract. 50 (2016) 69-83

14. M.K. Pradhan, Estimating the effect of process parameters on MRR, TWR and radial overcut of EDMed AISI D2 tool steel by RSM and GRA coupled with PCA, Int. J. Adv. Manufactur. Technol. 68 (2013) 591-605

15. K.P. Maity, D.K. Bagal, Effect of process parameters on the cut quality of stainless steel of plasma arc cutting using a hybrid approach, Int. J. Adv. Manufactur. Technol. 78 (2015) 161-175

16. A. Azadeh, S.F. Ghaderi, M. Fazli Ahmadabad, Multicriteria quality assessment of products by integrated DEAPCA approach, Int. J. Reliab. Qual. Safety Eng. 14 (2007) 201-218

17. A. Saha, S.C. Mondal, Multi-objective optimization of welding parameters in MMAW for nano-structured hardfacing material using GRA coupled with PCA, Trans. Indian Inst. Metals (2016) doi:10.1007/s12666-016-0945-1

18. Saha, S.C. Mondal, Experimental investigation and modeling of WEDM process for machining nano-structured hard facing material, J. Br. Soc. Mech. Sci. Eng. (2016) doi 10.1007/ s40430-016-0608-5

19. T.B. Rao, A.G. Krishna, Simultaneous optimization of multiple performance characteristics in WEDM for machining ZC63/SiCp MMC, Adv. Manufactur. 1 (2013) 265-275

20. A. Saha, H. Majumder, Performance analysis and optimization in turning of ASTM A36 through process capability index, J. King Saud Univ. Eng. Sci. (2016) http//dx.doi.org/ 10.1016/j.jksues.2016.11.002

21. M.H. Chen, L. Gao, J.H. Zhou, M. Wang, Application of reaction sintering to the manufacturing of a spacecraft combustion chamber of $\mathrm{SiC}$ ceramics, J. Mater. Process. Technol. 129 (2002) 408-411

22. Y. Fukuzawa, N. Mohri, H. Gotoh, T. Tani, Threedimensional machining of insulating ceramics materials with electrical discharge machining, Trans. Non-ferrous Metal Soc. China 19 (2009) s150-s156

23. J.A. Mc Geough, Advanced methods of machining (Springer; 1988)

24. W. König, D.F. Dauw, G. Levy, U. Panten. EDM-future steps towards the machining of the ceramics, CIRP Ann. Manufactur. Technol. 37 (1988) 623-631

25. K. Gupta, N.K. Jain, Analysis and optimization of microgeometry of miniature spur gears manufactured by wire electric discharge machining, Precis. Eng. 38 (2014) 728-737

26. K. Gupta, N.K. Jain, Comparative study of Wire-EDM and Hobbing for manufacturing high-quality miniature gears, Mater. Manufactur. Processes 29 (2014) 1470-1476

27. Y. Ziada, P. Koshy, Rotating curvilinear tools for EDM of polygonal shapes withsharp corners, CIRP Ann. Manufactur. Technol. 57 (2007) 221-224 
28. S. Kumar, An experimental study of the phenomenon of surface alloying by EDM process using Inconel tool electrode, ASME 2013 International Manufacturing Science and Engineering Conference Collocated with the 41st North American Manufacturing Research Conference, vol. 1 V001T01A040, 1-8. 10.1115/MSEC2013-1014

29. P. Friedrichs, T. Kimoto, L. Ley, G. Pensl, Silicon carbide 1: growth, defects, and novel applications (Wiley-VCH Verlag GmbH \& Co. KGaA, Weinheim, 2010)
30. G. Chi, Z. Wang, K. Xiao, K. Cui, B. Jin, The fabrication of a micro-spiral structure using EDM deposition in the air, J. Micro Mech. Microeng. 18 (2008) 1-9

31. P. Chaudhury, S. Samantaray, Finite element modelling of EDM of aluminum particulate metal matrix composites considering temperature dependent properties. Revue des Composites et des Materiaux Avances, Vol. 29, No. 1, pp. 53-62. (2019)

Cite this article as: Pallavi Chaudhury, Sikata Samantaray, Multi-optimization of process parameters for machining of a nonconductive SiC ceramic composite by non-conventional machining method, Manufacturing Rev. 7, 32 (2020) 